\title{
Fluoxetine Ameliorates Atopic Dermatitis-Like Skin Lesions in BALB/c Mice through Reducing Psychological Stress and Inflammatory Response
}

\author{
Yanxi Li1,2,3†, Long Chen ${ }^{1,2+}$, Yehong $\mathrm{Du}^{1,2+}$, Daochao Huang ${ }^{1,2}$, Huili Han ${ }^{1,2}$ and \\ Zhifang Dong ${ }^{1,2 *}$
}

${ }^{1}$ Chongqing Key Laboratory of Translational Medical Research in Cognitive Development and Learning and Memory Disorders, Children's Hospital of Chongqing Medical University, Chongqing, China, ${ }^{2}$ Ministry of Education Key Laboratory of Child Development and Disorders, Children's Hospital of Chongqing Medical University, Chongqing, China, ${ }^{3}$ The Chongqing Hospital of Traditional Chinese Medicine, Chongqing, China

OPEN ACCESS

Edited by: Annalisa Bruno,

University of Chieti-Pescara, Italy

Reviewed by:

Aida Habib,

American University of Beirut,

Lebanon

Zhi Zhang,

University of Science and Technology

of China, China

*Correspondence:

Zhifang Dong

zfdong@aliyun.com

tThese authors have contributed equally to this work.

Specialty section:

This article was submitted to Inflammation Pharmacology,

a section of the journal

Frontiers in Pharmacology

Received: 12 July 2016 Accepted: 02 September 2016 Published: 13 September 2016

Citation:

Li Y, Chen L, Du Y, Huang D, Han H and Dong $Z$ (2016) Fluoxetine

Ameliorates Atopic Dermatitis-Like Skin Lesions in BALB/c Mice through Reducing Psychological Stress and Inflammatory Response.

Front. Pharmacol. 7:318. doi: 10.3389/fphar.2016.00318
Atopic dermatitis (AD) is a common chronic inflammatory skin disorder, and patients with $A D$ suffer from severe psychological stress, which markedly increases the prevalence rate of depression and anxiety disorders in later life. Fluoxetine, a selective serotonin reuptake inhibitor, has recently been reported to exert anti-inflammatory and immunosuppressive effects. However, it is unclear whether fluoxetine is effective in the treatment of $A D$ through reducing psychological stress and inflammatory reaction. Here, we reported that a BALB/c mouse model of $A D$ was induced by application of 2,4dinitrochlorobenzene (DNCB) onto hairless dorsal skin. Chronic fluoxetine treatment (10 mg/kg per day, i.p.) significantly attenuated AD-like symptoms, as reflected by a dramatic decrease in scratching bouts, as well as a decrease in anxiety- and depressive-like behaviors. Furthermore, these behavioral changes were accompanied by a significant decrease in epidermal thickness, the number of mast cells in skin tissue, mRNA levels of interleukin-4 (IL-4) and IL-13 in the spleen, as well as serum immunoglobulin E (IgE) in the DNCB-treated mice by treatment with fluoxetine. Taken together, these results indicate that fluoxetine may suppress psychological stress and inflammatory response during $A D$ development, and subsequently ameliorate $A D$ symptoms, suggesting that fluoxetine may be a potential therapeutic agent against $A D$ in clinic.

Keywords: atopic dermatitis, fluoxetine, anti-inflammation, psychological stress, itching

\section{INTRODUCTION}

Atopic dermatitis (AD), also known as atopic eczema, is a common chronic inflammatory skin disease that is characterized by intense itching and recurrent eczematous lesions. The prevalence rate of $\mathrm{AD}$ is rising dramatically, especially in developed countries, and it now affects $10-30 \%$ of children and 1-10\% of adults (Leung et al., 2004; Montes-Torres et al., 2015; Weidinger and Novak, 2015), leading to a significant reduction in quality of life and economic burden 
(Berke et al., 2012). The pathogenesis of $\mathrm{AD}$ is not very clear, but it seems to be correlated with specific immune and inflammatory mechanisms. It has been reported that repeated applications of 2,4-dinitrochlorobenzene (DNCB) to mouse skin induced AD-like skin lesions, which is associated with a significant increase in serum immunoglobulin E (IgE) and T-helper (Th) 2 cytokines such as interleukin-4 (IL-4) and IL-13 at the chronic dermatitis site (Kitagaki et al., 1995; Harada et al., 2005). Further clinic studies have shown that these immunological changes are also observed in patients with AD (Leung et al., 2004; Liu et al., 2011). Therefore, most cases of AD currently are treated with emollients and topical anti-inflammatory agents such as topical corticosteroids and the topical calcineurin inhibitors. Many patients can be managed effectively, however, considerable number of patients still suffers from relapsing intolerable AD. In addition, these pharmacological therapies may cause various side effects including skin atrophy, telangiectases, purpura, and striae formation (Del Rosso and Friedlander, 2005). Thus, the use of less toxic alternative therapeutic agent against $\mathrm{AD}$ is imperative.

Meanwhile, a growing body of evidence has shown that patients with $\mathrm{AD}$ suffer from a severe psychological stress, which markedly increases the prevalence rate of depression and anxiety disorders (Wahlgren, 1992; Ginsburg et al., 1993; Hashiro and Okumura, 1997; Cheng et al., 2015), and in turn, stress may aggravate $\mathrm{AD}$ symptoms. Thus, reduction of depressive- and/or anxiety-related emotions by inhibiting psychological stress may be a potential method for the treatment of $\mathrm{AD}$. Indeed, previous studies have shown that paroxetine, a selective serotonin reuptake inhibitor (SSRI), is effective in the treatment of AD-like lesions in NC/Nga mice and chronic pruritus in patients (Zylicz et al., 2003; Jiang et al., 2007; Stander et al., 2009). Our recent study has reported that another SSRI fluoxetine, which has been widely used as an antidepressant agent in clinic, displayed antistress effects (Han et al., 2015). Furthermore, fluoxetine has also shown anti-inflammatory and direct immunosuppressive effects such as suppression of $\mathrm{T}$ cell activation, cytokine secretion and proliferation and induction of apoptosis in vitro and in vivo (Janssen et al., 2010; Gobin et al., 2013, 2014). Thus, it is reasonable to propose that fluoxetine may ameliorate $\mathrm{AD}$ through reducing psychological stress and inflammatory response.

To test this hypothesis, we treated BALB/c mice with DNCB to induce human $\mathrm{AD}$-like skin lesions, and assessed the inhibitory effect of fluoxetine on the development of dermatitis and to obtain basic information about the usefulness of fluoxetine in the treatment of $\mathrm{AD}$.

\section{MATERIALS AND METHODS}

\section{Animals}

Six-week-old male BALB/c mice were obtained from Chongqing Medical University Animal House Center and maintained at Children's Hospital of Chongqing Medical University Animal Care Centre. Animals were housed in plastic cages in a temperature-controlled $\left(21^{\circ} \mathrm{C}\right)$ colony room on a $12 / 12 \mathrm{~h}$ light/dark cycle. Food and water were available ad libitum. All experiments and procedures were approved by Chongqing
Medical University Animal Care and Use Committee. All efforts were made to minimize the number of animals used.

\section{Drugs}

Fluoxetine and DNCB were purchased from Sigma-Aldrich Co. (St. Louis, MO, USA). DNCB was dissolved in acetone-olive oil $(4: 1, \mathrm{v} / \mathrm{v})$ and fluoxetine was dissolved in $0.9 \%$ sterile saline at a concentration of $10 \mathrm{mg} / \mathrm{ml}$. The drug application and experimental tests were performed in a double-blinded manner.

\section{Induction of AD-Like Skin Lesions and Fluoxetine Treatment}

Induction of $\mathrm{AD}$-like skin lesions procedure is described in Figure 1 as described previously (Kim S. R. et al., 2014). The backs of mice were shaved with an electric clipper and depilatory cream a day before DNCB sensitization. The DNCB sensitization and challenge were performed for 5 weeks. For the sensitization process, a $1 \mathrm{~cm} \times 1 \mathrm{~cm}$ gauze-attached patch was applied with $200 \mu \mathrm{l}$ of $1 \%$ DNCB and attached to the shaved area twice per week. Two weeks after sensitization, the back skin was challenged with $200 \mu \mathrm{l}$ of a $0.2 \%$ DNCB solution twice per week. This procedure was repeated for 3 weeks and fluoxetine was intraperitoneally administrated together. Behavioral tests were performed within 3 days after DNCB and fluoxetine treatments. At the end of the experiment, mice were sacrificed and samples were collected to evaluate the effects of DNCB and fluoxetine treatments (Figure 1).

\section{Clinical Scoring of Skin Lesions}

The severity of DNCB-induced skin lesions was clinically assessed as previously described (Matsuda et al., 1997; Kim et al., 2008). Briefly, the total clinical severity score for skin lesions was calculated as the sum of the individual scores ( 0 , no symptom; 1 , mild; 2 , moderate; 3 , severe) for the following four AD signs and symptoms: erythema/hemorrhage, edema, excoriation/erosion, and scaling/dryness.

\section{Scratching Behavior}

The animals were placed into an observation chamber for $10 \mathrm{~min}$ for acclimatization before the measurement of scratching behavior. The scratching behavior was defined as the hind limb scratches directed to the shaved area. The number of scratching behaviors was counted for $30 \mathrm{~min}$ each time.

\section{Elevated Plus Maze}

Mice were placed in the center of a plus maze (each arm $30 \mathrm{~cm}$ ) that was elevated $50 \mathrm{~cm}$ above the floor with two opposite open arms and two opposite closed arms (10-cm-tall walls on the closed arms) arranged at right angles. The number of entries and time spent in the closed and open arms were monitored for 10 min by ANY-Maze Video Tracking System. The maze was cleaned with $70 \%$ ethanol and water between tests.

\section{Forced Swimming}

Mice were placed in a cylinder of water (temperature $24-25^{\circ} \mathrm{C}$; $10 \mathrm{~cm}$ in diameter, $30 \mathrm{~cm}$ in height) for $10 \mathrm{~min}$. The depth of 


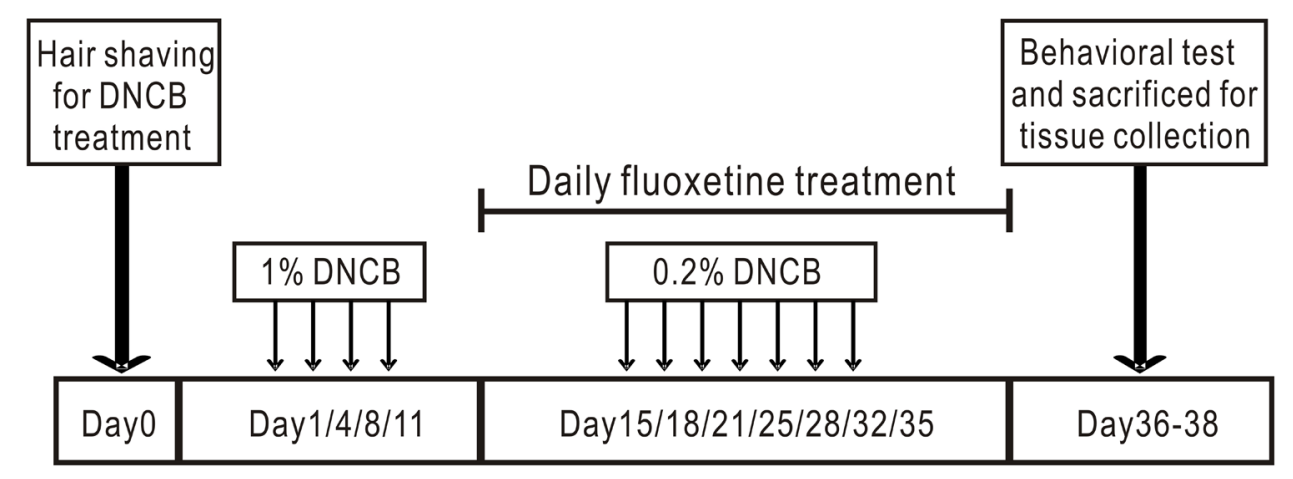

FIGURE 1 | Experimental protocol for induction of atopic dermatitis in mouse model. The back skin of mice was applied repeatedly with DNCB for 5 weeks to induce AD. Fluoxetine was intraperitoneally administrated from the third week together with DNCB.

water was set to prevent animals from touching the bottom with their hind limbs. The latency to immobility, which was defined as floating or the least movement to maintain the head above the water, was recorded by ANY-Maze Video Tracking System (Stoelting Co.) from the side.

\section{Histological Analysis}

A portion of the skin biopsies were fixed in 4\% paraformaldehyde. The skin sections ( $4 \mu \mathrm{m}$ thick) were stained with hematoxylin and eosin (H\&E) to evaluate the epidermal hyperplasia and the other sections were stained with toluidine blue to evaluate the infiltration of mast cells. Mast cells were counted in five parts of high-power fields $(\mathrm{HPF})$ at $400 \times$ magnification.

\section{Measurement of Serum IgE}

Blood samples were collected by cardiac puncture under anesthesia, and sera were collected by centrifugation and stored at $-80^{\circ} \mathrm{C}$ until use. Total IgE levels in plasma were determined by sandwich ELISA using the Sigma mouse IgE ELISA kit (St. Louis, MO, USA).

\section{Cytokine Analysis by Real-Time PCR}

Total RNA was extracted from spleen tissue with the TRIzol reagent (Takara, Otsu, Shiga, Japan) according to the manufacturer's instruction. The quantity and purity of total RNA were determined with a Nanodrop reader (Nanodrop Technologies, Wilmington, DE, USA). One microgram of total RNA was converted to the first-strand DNA with PrimeScript RT reagent Kit with gDNA Eraser (Takara, Otsu, Shiga, Japan) reverse transcriptase (Takara, Otsu, Shiga, Japan) and RNAsin (Takara, Otsu, Shiga, Japan). cDNA was amplified using gene-specific primers and $\mathrm{SYBR}^{\circledR}$ Premix Ex Taq ${ }^{\mathrm{TM}}$ II (Takara, Otsu, Shiga, Japan). Primer sequences were as follows: Interferon- $\gamma$ (IFN- $\gamma$ ) (forward: $5^{\prime}$-CTCAAGTGGCATAGATGT-3', reverse: 5'-GAGATAATCTGGCTCTGCAGGATT-3'); IL-2 (forward: $5^{\prime}$ -CTCTACAGCGGAAGCACAGCA-3', reverse: 5'-TGCCGCA GAGGTCCAAGTT-3'); IL-4 (forward: 5'-TGAACGAGGTCA CAGGAGAAGG-3', reverse: 5'-CACCTTGGAAGCCCTACA GACA-3'); IL-13 (forward: 5'-AGCATGGTATGGAGTGTGG
ACCTG-3', reverse: 5' -CAGTTGCTTTGTGTAGCTGAGCAG$3^{\prime}$ ); $\beta$-actin (forward: 5'-GCACCACACCTTCTACAATGAGC$3^{\prime}$, reverse: 5'-GGATAGCAGCCTGGATAGCAAC-3'). The relative expression levels of target genes were normalized using $\beta$-actin as an internal control.

\section{Statistical Analyses}

All data are expressed as the mean \pm SEM. Statistical analysis of the results were performed by one-way analysis of variance (ANOVA) followed by Turkey's test. Significance level was set at $p<0.05$.

\section{RESULTS}

\section{Chronic Fluoxetine Treatment Alleviates DNCB-Induced AD Symptoms}

Previous studies have shown that paroxetine, a selective SSRI, is effective in the treatment of $\mathrm{AD}$ in both animal model and patients, with no apparent side-effects (Zylicz et al., 2003; Jiang et al., 2007; Stander et al., 2009). To determine whether fluoxetine is effective in the treatment of $\mathrm{AD}$-like skin lesions, we chronically treated $\mathrm{AD}$ mice with fluoxetine $(10 \mathrm{mg} / \mathrm{kg}$, i.p.; Figure 1). Consistent with previous reports (Kim H. et al., 2014; Kim S. R. et al., 2014; Yoon et al., 2015), AD-like lesions developed following repeated application of DNCB to the back skin (Figure 2A). More importantly, chronic fluoxetine administration dramatically alleviated skin lesions (Figure 2A). To further compare the skin lesions of the mice with those of human AD (Mihm et al., 1976; Piloto Valdes et al., 1990), clinical severity of the dermatitis was scored as previously described (Leung et al., 1990). The result showed that DNCB treatment significantly increased the skin lesion score compared with normal control, whereas the skin lesion score was significantly decreased after fluoxetine treatment (control: $n=10$; DNCB: $n=10$; DNCB+fluoxetine: $n=14$; Figure 2B). In addition, chronic fluoxetine treatment significantly suppressed DNCB-induced scratching behaviors (control: $n=10$; DNCB: $n=10$; DNCB+fluoxetine: $n=14$; Figure 2C). Taken together, these 
A

\section{control}

DNCB

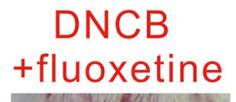

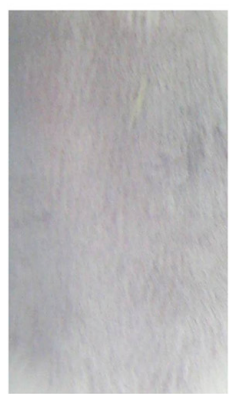
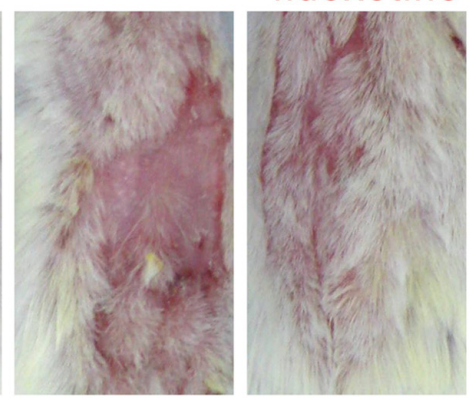

B
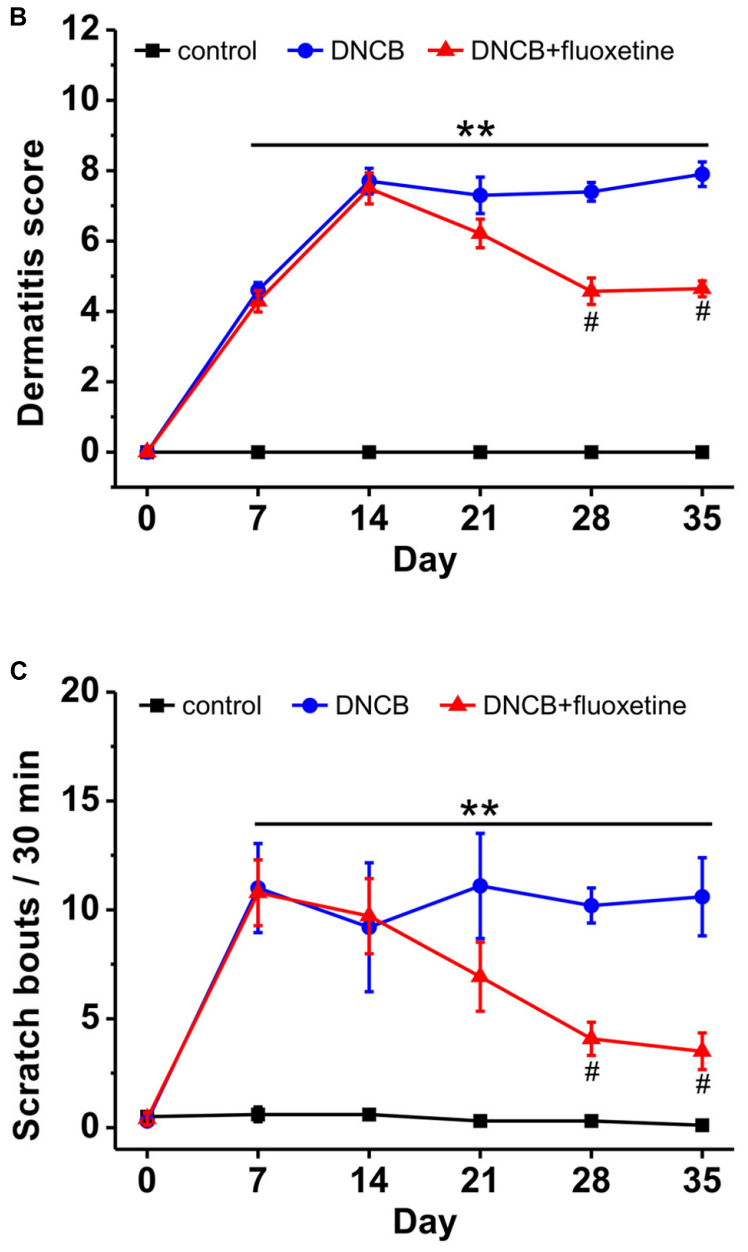

FIGURE 2 | The preventive effect of chronic fluoxetine treatment on AD-like skin lesions induced by DNCB treatment. (A) Photographs showing skin lesions in the different groups of experimental mice. (B) The severity of clinical symptoms of the skin lesions was evaluated

macroscopically and calculated as the sum of the individual scores once a week for the following four AD signs and symptoms: erythema/hemorrhage, edema, excoriation/erosion and scaling/dryness. (C) The frequency of scratching behavior was observed and calculated once a week in the different treatment group. $n=10$ for control and DNCB, $n=14$ for DNCB+fluoxetine. ${ }^{* *} P<0.01$ compared with control, and ${ }^{\#} p<0.05$ compared with DNCB group. results suggest that chronic fluoxetine treatment alleviates the DNCB-induced skin lesions.

\section{Chronic Fluoxetine Treatment Reduces Depressive- and Anxiety-Like Behaviors in $A D$ Mice}

A growing body of evidence has shown that $\mathrm{AD}$ in both adolescence and adulthood increases the risk of developing major depression and anxiety disorders in later life (Wahlgren, 1992; Ginsburg et al., 1993; Hashiro and Okumura, 1997; Cheng et al., 2015), and fluoxetine has been widely used as an antidepressant agent in clinic. Thus, we next introduced different behavioral tests, including forced swimming and elevated plus maze, to determine whether the alleviating effect of fluoxetine on $\mathrm{AD}$ is associated with its antipsychotic effect. Compared to normal controls, $\mathrm{AD}$ mice displayed apparent depressive-like symptom, as reflected by much shorter latency to immobility during forced swimming test (control: $n=10$, $186.8 \pm 5.0$ s; DNCB: $n=10,157.2 \pm 10.4$ s, $p<0.05$ vs. control; Figure 3A). In agreement with an anti-depressive effect of fluoxetine, it succeeded in abolishing the influence of DNCB on depressive behavior (DNCB+fluoxetine: $n=14$, $228.3 \pm 15.2$ s, $p<0.05$ vs. control, $p<0.01$ vs. DNCB; Figure 3A).

Next, using elevated plus maze paradigm, we tested the effect of fluoxetine on anxiety-like behavior in AD. The results showed that both the number of entry into open arms (control: $n=10$, $25.5 \pm 3.9$; DNCB: $n=10,11.1 \pm 1.5, p<0.05$ vs. control; Figure 3B) and the time spent in open arms (control: $n=10$, $40.2 \pm 5.5$ s; DNCB: $n=10,11.1 \pm 3.1 \mathrm{~s}, p<0.05$ vs. control; Figure 3C) were significantly reduced in DNCB-treated mice during elevated plus maze test. Similar to forced swimming test, chronic fluoxetine treatment was able to restore the number of entry into the open arms (DNCB+fluoxetine: $n=14,34.9 \pm 4.9$, $p<0.05$ vs. control, $p<0.01$ vs. DNCB; Figure 3B) and the time in open arms (DNCB+fluoxetine: $n=14,61.7 \pm 10.8 \mathrm{~s}, p<0.05$ vs. control, $p<0.01$ vs. DNCB; Figure 3C) to control levels, indicating chronic fluoxetine administration reduces anxiety during $\mathrm{AD}$ development.

\section{Chronic Fluoxetine Treatment Suppresses Tissue Inflammation and the Accumulation of Mast Cells in AD-Like Skin Lesions}

It has been widely accepted that $\mathrm{AD}$ is a common chronic inflammatory skin disease. We next wanted to determine the alterations of tissue inflammation and the accumulation of mast cells in AD-like skin lesions. Consistent with previous reports (Kim S. R. et al., 2014; Yoon et al., 2015), histopathological examination showed that the skins of the DNCB-treated group showed markedly epidermal hyperplasia as compared to the normal group, whereas this hyperplasia was significantly reduced by chronic fluoxetine treatment (control: $n=10,17.0 \pm 1.8 \mu \mathrm{m}$; DNCB: $n=10,83.4 \pm 13.2 \mu \mathrm{m}, p<0.01$ vs. control; DNCB+fluoxetine: $n=14,54.9 \pm 5.8 \mu \mathrm{m}, p<0.01$ vs. control, $p<0.05$ vs. DNCB; Figures 4A,B). Similarly, the 


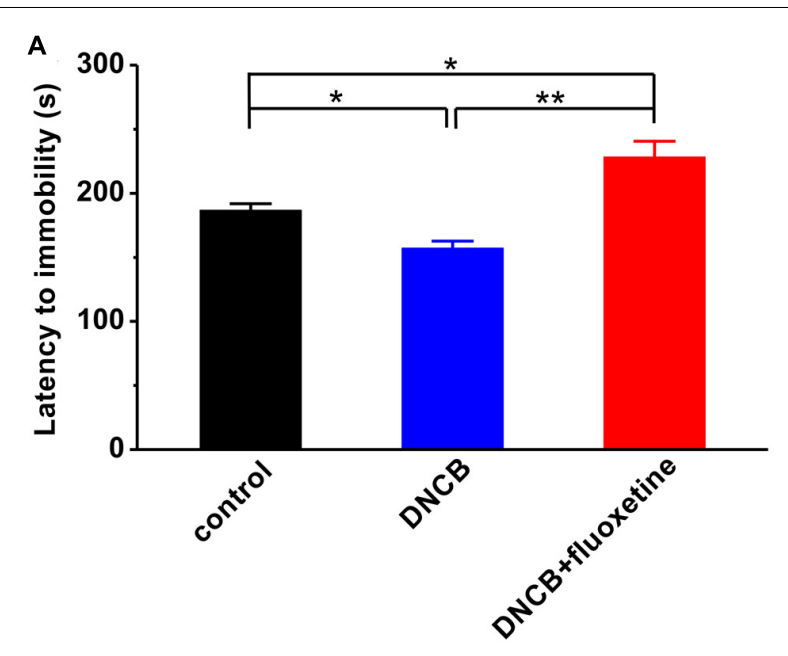

B

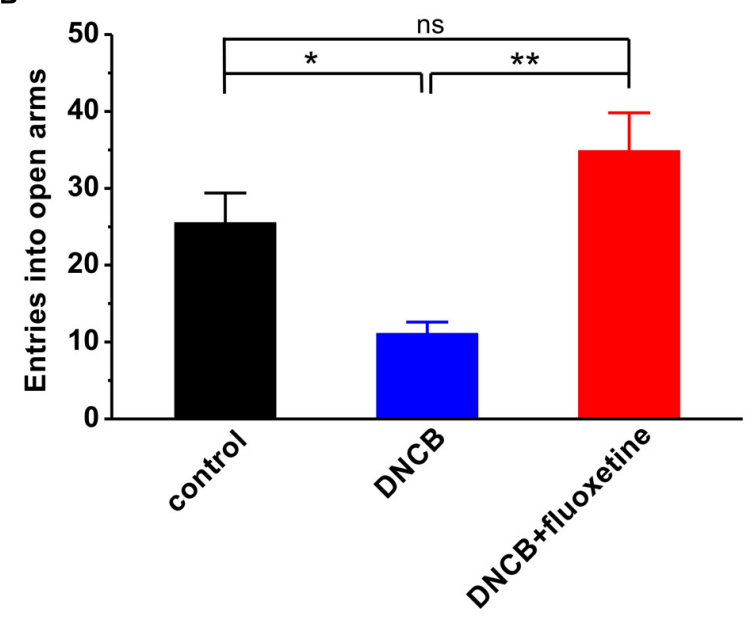

C

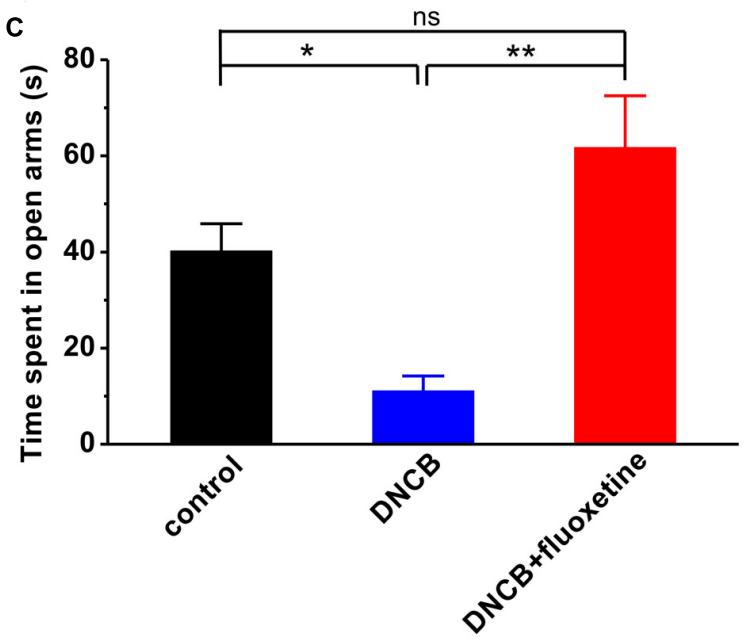

FIGURE 3 | Effects of chronic fluoxetine treatment on depressive- and anxiety-like behaviors induced by DNCB treatment. (A) The latency to immobility was measured during forced swimming test in the different groups of experimental mice. Both the number of entries into open arms (B) and the time spent in open arms (C) were measured during elevated plus maze test. $n=10$ for control and DNCB, $n=14$ for DNCB+fluoxetine. ${ }^{*} P<0.05$, $* * P<0.01$ number of mast cells in the dermis of DNCB-treated mice was markedly increased as compared to the normal group, whereas this increment was significantly suppressed by chronic fluoxetine treatment (control: $n=10,8.5 \pm 1.7$; DNCB: $n=10,88.0 \pm 8.5, p<0.01$ vs. control; $\mathrm{DNCB}+$ fluoxetine: $n=14,57.3 \pm 7.8, p<0.01$ vs. control, $p<0.05$ vs. $\mathrm{DNCB}$; Figures $4 \mathrm{C}, \mathrm{D})$.

\section{Chronic Fluoxetine Treatment Inhibits DNCB-Induced Serum IgE Elevation}

Since serum IgE level is correlated with the severity of AD (Arshad and Holgate, 2001; Belloni et al., 2008; Ibler and Jemec, 2015; Montes-Torres et al., 2015), and the level of IgE is associated with Th2 or Th1 immunity (Snapper and Paul, 1987), we examined the serum level of $\operatorname{IgE}$ to evaluate the effect of fluoxetine on systemic Th1 and Th2 immunities in DNCB-treated mice. As shown in Figure 5, the serum level of IgE was markedly increased in the DNCBtreated group compared to normal control (control: $n=4$, $11.1 \pm 1.9 \mu \mathrm{g} / \mathrm{ml}$; DNCB: $n=6,19.6 \pm 2.8 \mu \mathrm{g} / \mathrm{ml}, p<0.01$ vs. control; Figure 5). Chronic fluoxetine treatment restored the serum IgE to normal control level (DNCB+fluoxetine: $n=5$, $11.6 \pm 0.4 \mu \mathrm{g} / \mathrm{ml}, p>0.05$ vs. control, $p<0.05$ vs. DNCB; Figure 5).

\section{Chronic Fluoxetine Treatment Reduces Spleen Cytokines in AD Mice}

In the past decades, SSRIs including fluoxetine have been shown to exert several immunological effects, such as alteration of cytokine secretion (Janssen et al., 2010; Gobin et al., 2013, 2014). To evaluate the effects of fluoxetine on Th1 and Th2 immunities in $\mathrm{AD}$, we examined the expression of IL-2, IFN$\gamma$, IL-4, and IL-13 mRNAs in the spleen of experimental mice. The results showed that the IL-4 (control: $n=4$, $100.0 \pm 14.7$; DNCB: $n=4,288.6 \pm 7.1, p<0.01$ vs. control; Figure 6A) and IL-13 (control: $n=6,100.0 \pm 6.5$; DNCB: $n=5,212.5 \pm 36.1, p<0.05$ vs. control; Figure 6B) mRNA expressions were dramatically increased, whereas the IL2 (control: $n=6,100.0 \pm 18.0$; DNCB: $n=6,84.0 \pm 11.5$, $p>0.05$ vs. control; DNCB+fluoxetine: $n=5,99.1 \pm 12.6$, $p>0.05$ control, $p>0.05$ vs. DNCB; Figure 6C) and IFN $-\gamma$ (control: $n=6,100.0 \pm 17.6$; DNCB: $n=6,126.8 \pm 4.4$, $p>0.05$ vs. control; $\mathrm{DNCB}$ +fluoxetine: $n=6,102.6 \pm 12.9$, $p>0.05$ control, $p>0.05$ vs. DNCB; Figure 6D) mRNA expressions remained unchanged in DNCB-treated mice as compared to the normal group. More importantly, chronic fluoxetine treatment suppressed the DNCB-induced increase of IL-4 (DNCB+fluoxetine: $n=5,145.2 \pm 42.3, p>0.05$ control, $p<0.05$ vs. DNCB; Figure 6A) and IL-13 mRNA expressions (DNCB+fluoxetine: $n=6,132.1 \pm 27.3, p>0.05$ control, $p<0.05$ vs. DNCB; Figure 6B)

\section{DISCUSSION}

In the present study, we confirm that repeated DNCB treatment induces the $\mathrm{AD}$-like pathology, and demonstrate that chronic 


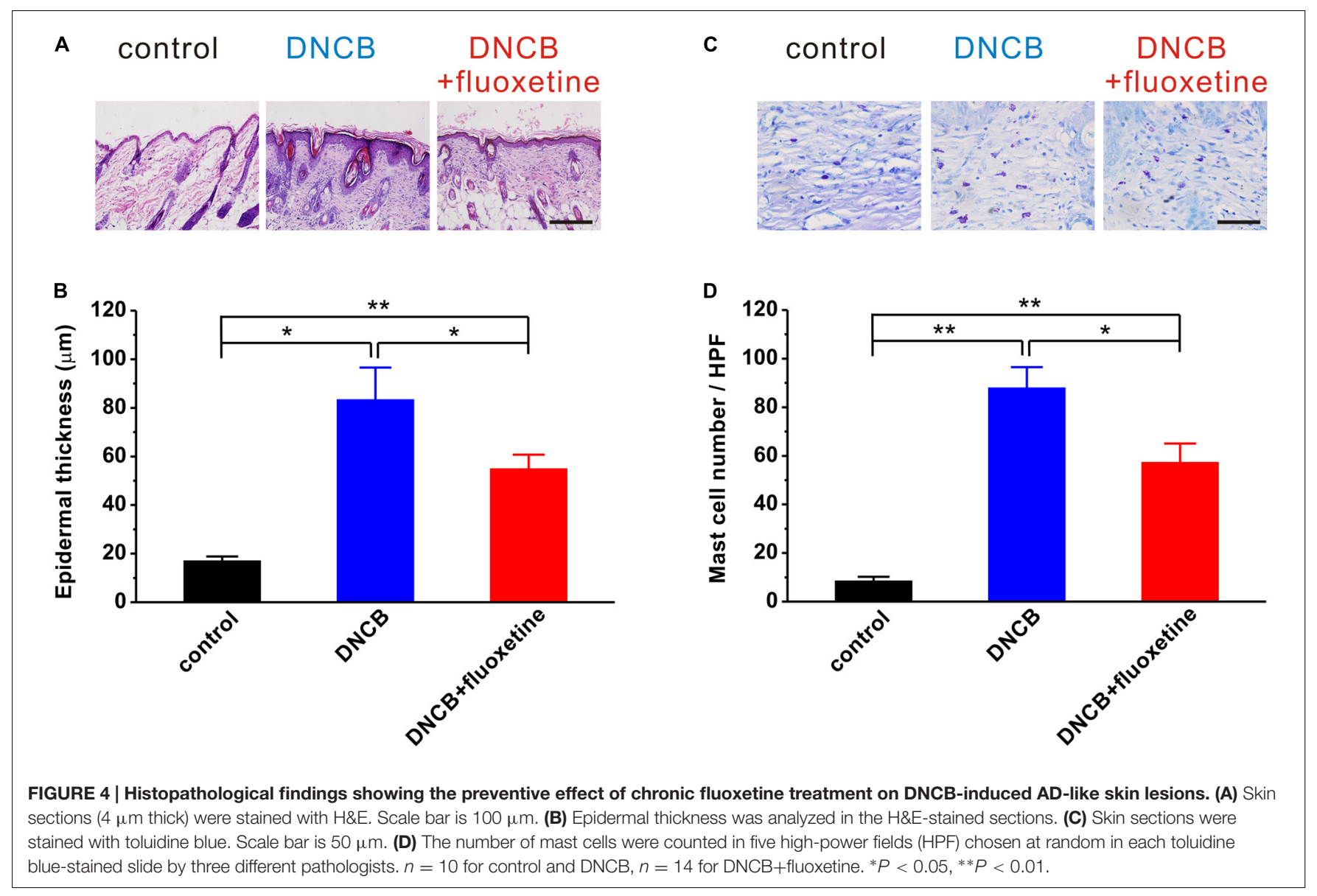

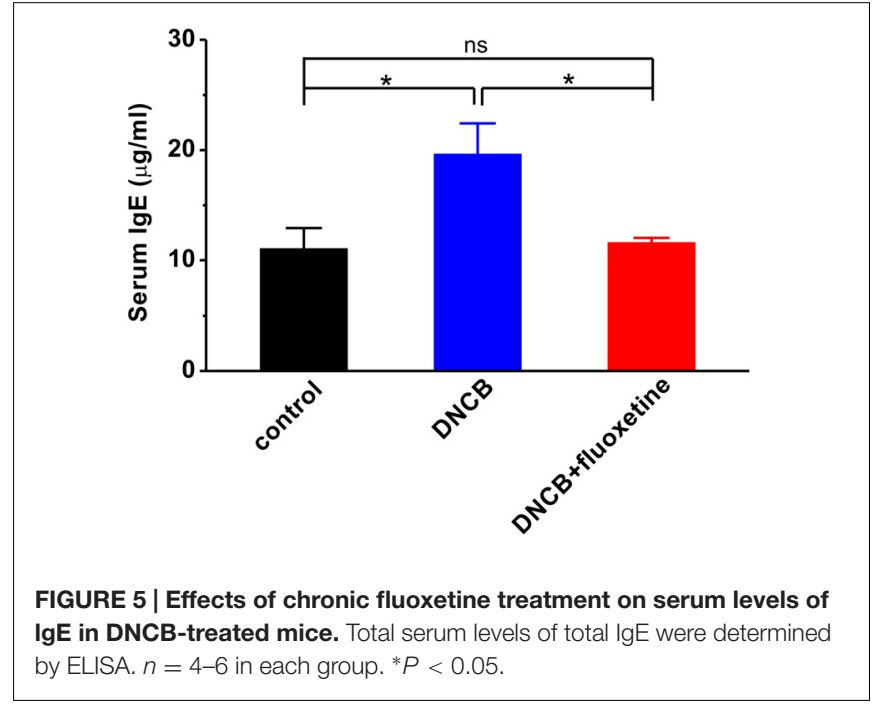

fluoxetine treatment reduces DNCB-induced inflammatory response and subsequently ameliorate $\mathrm{AD}$ symptoms in $\mathrm{BALB} / \mathrm{c}$ mice. Therefore, our current results indicate that fluoxetine may effectively prevent $\mathrm{AD}$ symptoms.

It has been reported that SSRI such as paroxetine can inhibit the development of AD-like lesions in NC/Nga mice and alleviate chronic pruritus in patients (Zylicz et al., 2003; Jiang et al., 2007; Stander et al., 2009). However, the underlying mechanism of antipruritic effect of SSRI remains unclear at present. It is well documented that $\mathrm{AD}$ is an inflammatory skin disease characterized by pruritic and eczematous skin lesions, extensive inflammatory cell infiltration and release of proinflammatory mediators (Morar et al., 2006). Previous study has shown that IgE expression causes both acute and chronic phase skin inflammations, suggesting that the upregulation of total serum IgE may be a hallmark of AD (Arshad and Holgate, 2001). Further study has shown that the level of IgE is associated with Th2 or Th1 immunity, in turn, Th2 has powerful effect in stimulating the expression of $\operatorname{IgE}$ (Snapper and Paul, 1987). Therefore, although the mechanism for the anti-AD action of fluoxetine remains unclear, the downregulation of serum IgE and Th2 immunity may be a principal mechanism for the fluoxetine action. Indeed, in the present study, we found that chronic fluoxetine treatment reduced total IgE level and suppressed Th2 such as IL-4 and IL-13 mRNA expressions in DNCB-treated mice. This hypothesis is further supported by more recent reports. For example, SSRIs including fluoxetine have been shown to exert several immunosuppressive effects, such as decreased lymphocyte proliferation and reduced pro-inflammatory cytokine secretion (Janssen et al., 2010; Gobin et al., 2013, 2014). On the other 

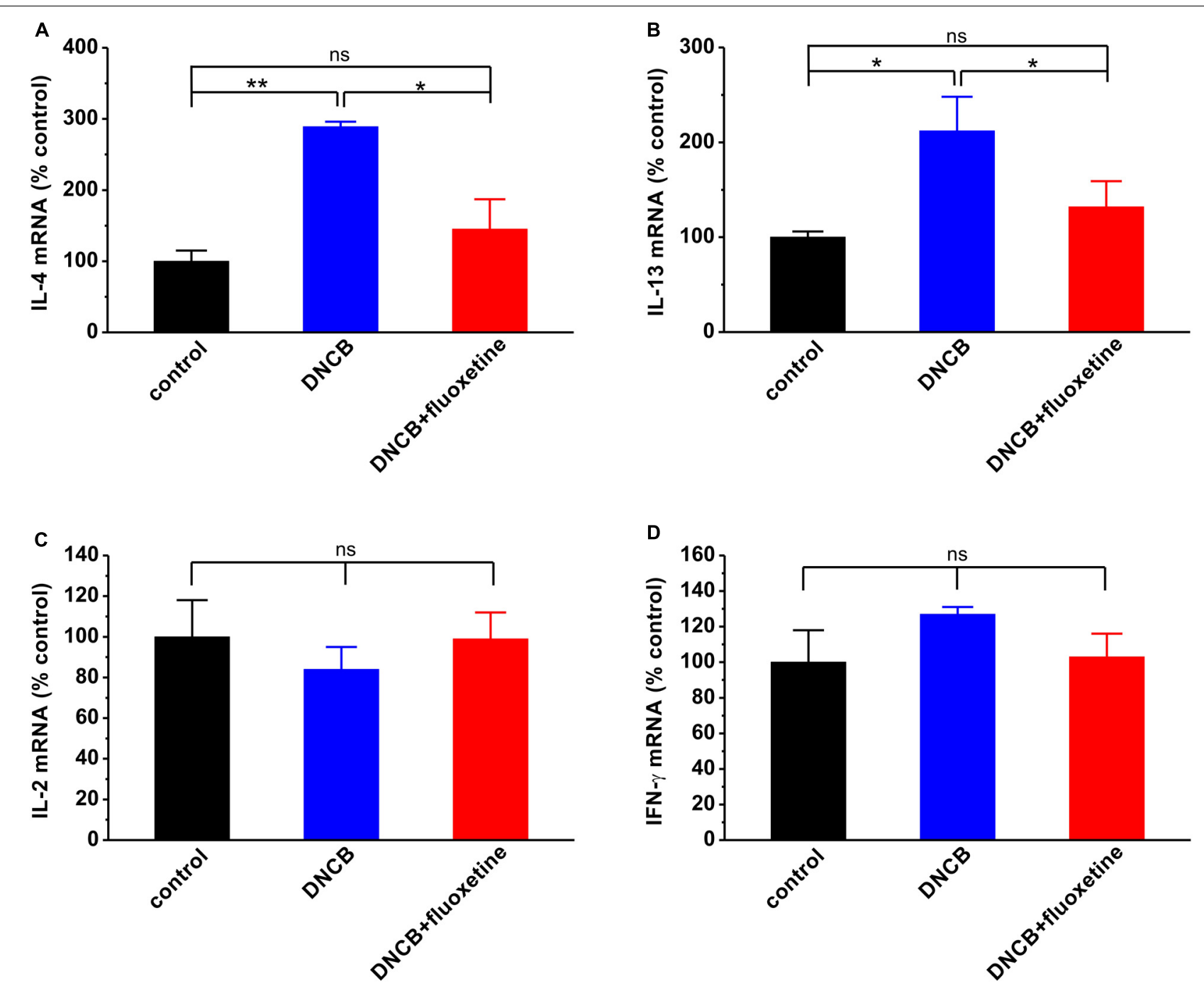

FIGURE 6 | Effects of chronic fluoxetine treatment on mRNA expressions of cytokines. IL-4 (A), IL-13 (B), IL-2 (C) and IFN- $\gamma$ (D) mRNA expressions were determined by real-time PCR. $n=4-6$ in each group. ${ }^{*} P<0.05,{ }^{*} P<0.01$.

hand, fluoxetine significantly decreases lymphocyte proliferation, which is resulted from elevated central serotonin (5-HT) neurotransmission and activation of central 5-HT2 receptors (Pellegrino and Bayer, 2002). In addition, fluoxetine also can exert immunosuppressive effect via suppressing intracellular $\mathrm{Ca}^{2+}$ signaling in Jurkat $\mathrm{T}$ lymphocytes through depletion of $\mathrm{Ca}^{2+}$ from intracellular stores (Gobin et al., 2015).

Alternatively, fluoxetine may modulate psycho-emotion and subsequently prevent $\mathrm{AD}$ symptoms. Previous study has shown that the majority of patients with $\mathrm{AD}$ are subjected to psychological stress, and in turn, stress aggravates their pruritus, suggesting that pruritus might be closely related with emotional distress in AD (Wahlgren, 1992). Fluoxetine is frequently used in clinic to treat neuropsychiatric disorders, such as major depressive disorder, obsessivecompulsive disorder, post-traumatic stress disorder, and anxiety disorder (McIntyre and Katzman, 2003; Pinna et al., 2009). Thus, it is reasonable to assume that fluoxetine may play anti-AD action through the inhibition of psychological stress. Indeed, in the present study, we found that chronic fluoxetine treatment led to a significant decrease in DNCBinduced depressive- and anxiety-like behaviors (Figure 3). Notably, chronic treatment with fluoxetine impairs adult neurogenesis and locomotor activity in mice (Ohira and Miyakawa, 2011; Zheng et al., 2011). Thus, future experiments determining the potential side effects of chronic treatment with fluoxetine will be helpful to fluoxetine in the treatment of $\mathrm{AD}$.

In summary, we demonstrate that chronic fluoxetine treatment is an effective means to reduce DNCB-induced scratching bouts, depressive/anxiety-like behaviors, skin lesions and serum IgE levels in mice model of $\mathrm{AD}$, and these effects are mediated by regulating pro-inflammatory cytokines, such as 
IL-4 and IL-13. These results suggest that fluoxetine may be a potential therapeutic agent against $\mathrm{AD}$ in clinic; nevertheless, further investigations would be necessary to clarify its molecular mechanisms of action in AD.

\section{AUTHOR CONTRIBUTIONS}

YL, LC, YD, and DH performed the research. $\mathrm{HH}$ and $\mathrm{ZD}$ designed the research study. $\mathrm{YL}, \mathrm{HH}$, and $\mathrm{ZD}$ contributed essential reagents or tools. YL, LC, YD, and ZD analyzed the data. $\mathrm{HH}$ and $\mathrm{ZD}$ wrote the manuscript.

\section{REFERENCES}

Arshad, S. H., and Holgate, S. (2001). The role of IgE in allergen-induced inflammation and the potential for intervention with a humanized monoclonal anti-IgE antibody. Clin. Exp. Allergy 31, 1344-1351. doi: 10.1046/j.13652222.2001.01162.x

Belloni, B., Andres, C., Ollert, M., Ring, J., and Mempel, M. (2008). Novel immunological approaches in the treatment of atopic eczema. Curr. Opin. Allergy Clin. Immunol. 8, 423-427. doi: 10.1097/ACI.0b013e32830fb8fd

Berke, R., Singh, A., and Guralnick, M. (2012). Atopic dermatitis: an overview. Am. Fam. Physician 86, 35-42.

Cheng, C. M., Hsu, J. W., Huang, K. L., Bai, Y. M., Su, T. P., Li, C. T., et al. (2015). Risk of developing major depressive disorder and anxiety disorders among adolescents and adults with atopic dermatitis: a nationwide longitudinal study. J. Affect. Disord. 178, 60-65. doi: 10.1016/j.jad.2015.02.025

Del Rosso, J., and Friedlander, S. F. (2005). Corticosteroids: options in the era of steroid-sparing therapy. J. Am. Acad. Dermatol. 53, S50-S58. doi: 10.1016/j.jaad.2005.04.030

Ginsburg, I. H., Prystowsky, J. H., Kornfeld, D. S., and Wolland, H. (1993). Role of emotional factors in adults with atopic dermatitis. Int. J. Dermatol. 32, 656-660. doi: 10.1111/j.1365-4362.1993.tb04021.x

Gobin, V., De Bock, M., Broeckx, B. J., Kiselinova, M., De Spiegelaere, W., Vandekerckhove, L., et al. (2015). Fluoxetine suppresses calcium signaling in human T lymphocytes through depletion of intracellular calcium stores. Cell Calcium 58, 254-263. doi: 10.1016/j.ceca.2015.06.003

Gobin, V., Van Steendam, K., Denys, D., and Deforce, D. (2014). Selective serotonin reuptake inhibitors as a novel class of immunosuppressants. Int. Immunopharmacol. 20, 148-156. doi: 10.1016/j.intimp.2014.02.030

Gobin, V., Van Steendam, K., Fevery, S., Tilleman, K., Billiau, A. D., Denys, D., et al. (2013). Fluoxetine reduces murine graft-versus-host disease by induction of T cell immunosuppression. J. Neuroimmune Pharmacol. 8, 934-943. doi: 10.1007/s11481-013-9463-7

Han, H., Dai, C., and Dong, Z. (2015). Single fluoxetine treatment before but not after stress prevents stress-induced hippocampal long-term depression and spatial memory retrieval impairment in rats. Sci. Rep. 5:12667. doi: $10.1038 /$ srep 12667

Harada, D., Takada, C., Tsukumo, Y., Takaba, K., and Manabe, H. (2005). Analyses of a mouse model of the dermatitis caused by 2,4,6-trinitro-1chlorobenzene (TNCB)-repeated application. J. Dermatol. Sci. 37, 159-167. doi: 10.1016/j.jdermsci.2004.11.007

Hashiro, M., and Okumura, M. (1997). Anxiety, depression and psychosomatic symptoms in patients with atopic dermatitis: comparison with normal controls and among groups of different degrees of severity. J. Dermatol. Sci. 14, 63-67. doi: 10.1016/S0923-1811(96)00553-1

Ibler, K. S., and Jemec, G. B. (2015). Novel investigational therapies for atopic dermatitis. Expert Opin. Investig. Drugs 24, 61-68. doi: 10.1517/13543784.2015.957756

Janssen, D. G., Caniato, R. N., Verster, J. C., and Baune, B. T. (2010). A psychoneuroimmunological review on cytokines involved in antidepressant treatment response. Hum. Psychopharmacol. 25, 201-215. doi: 10.1002/hup.1103

\section{ACKNOWLEDGMENTS}

This work was supported by 973 Program of the Ministry of Science and Technology of the People's Republic of China (2014CB548100 to ZD), the National Natural Science Foundation of China (81271221 and 81571042 to ZD, 81501143 to $\mathrm{HH}$ ), the Natural Science Foundation of Chongqing (cstc2015jcyjA00037 to $\mathrm{HH}$, cstc2016jcyjA0298 to YL), the Medicine Scientific Research Project of Chongqing Health Bureau (2015MSXM079 to YL) and the Graduate Research Innovation Project of Chongqing (CYS15117 to LC).

Jiang, J., Kuhara, T., Ueki, R., Zheng, Y., Suto, H., Ikeda, S., et al. (2007). Inhibitory effects of paroxetine on the development of atopic dermatitis-like lesions in NC/Nga mice. J. Dermatol. Sci. 47, 244-247. doi: 10.1016/j.jdermsci.2007. 05.006

Kim, E. C., Lee, H. S., Kim, S. K., Choi, M. S., Lee, S., Han, J. B., et al. (2008). The bark of Betula platyphylla var. japonica inhibits the development of atopic dermatitis-like skin lesions in NC/Nga mice. J. Ethnopharmacol. 116, 270-278. doi: 10.1016/j.jep.2007.11.042

Kim, H., Kim, J. R., Kang, H., Choi, J., Yang, H., Lee, P., et al. (2014). 7,8,4'-trihydroxyisoflavone attenuates DNCB-induced atopic dermatitis-like symptoms in NC/Nga mice. PLoS ONE 9:e104938. doi: 10.1371/journal.pone.0104938

Kim, S. R., Choi, H. S., Seo, H. S., Ku, J. M., Hong, S. H., Yoo, H. H., et al. (2014). Oral administration of herbal mixture extract inhibits 2,4dinitrochlorobenzene-induced atopic dermatitis in BALB/c mice. Mediators Inflamm. 2014:319438. doi: 10.1155/2014/319438

Kitagaki, H., Fujisawa, S., Watanabe, K., Hayakawa, K., and Shiohara, T. (1995). Immediate-type hypersensitivity response followed by a late reaction is induced by repeated epicutaneous application of contact sensitizing agents in mice. J. Invest. Dermatol. 105, 749-755. doi: 10.1111/1523-1747.ep12325538

Leung, D. Y., Boguniewicz, M., Howell, M. D., Nomura, I., and Hamid, Q. A. (2004). New insights into atopic dermatitis. J. Clin. Invest. 113, 651-657. doi: 10.1172/JCI21060E1

Leung, D. Y., Hirsch, R. L., Schneider, L., Moody, C., Takaoka, R., Li, S. H., et al. (1990). Thymopentin therapy reduces the clinical severity of atopic dermatitis. J. Allergy Clin. Immunol. 85, 927-933. doi: 10.1016/0091-6749(90)90079-J

Liu, F. T., Goodarzi, H., and Chen, H. Y. (2011). IgE, mast cells, and eosinophils in atopic dermatitis. Clin. Rev. Allergy. Immunol. 41, 298-310. doi: 10.1007/s12016-011-8252-4

Matsuda, H., Watanabe, N., Geba, G. P., Sperl, J., Tsudzuki, M., Hiroi, J., et al. (1997). Development of atopic dermatitis-like skin lesion with IgE hyperproduction in $\mathrm{NC/Nga} \mathrm{mice.} \mathrm{Int.} \mathrm{Immunol.} \mathrm{9,} \mathrm{461-466.} \mathrm{doi:}$ 10.1093/intimm/9.3.461

McIntyre, R., and Katzman, M. (2003). The role of atypical antipsychotics in bipolar depression and anxiety disorders. Bipolar Disord. 5(Suppl. 2), 20-35. doi: 10.1111/j.1399-2406.2003.00061.x

Mihm, M. C. Jr., Soter, N. A., Dvorak, H. F., and Austen, K. F. (1976). The structure of normal skin and the morphology of atopic eczema. J. Invest. Dermatol. 67, 305-312. doi: 10.1111/1523-1747.ep12514346

Montes-Torres, A., Llamas-Velasco, M., Perez-Plaza, A., Solano-Lopez, G., and Sanchez-Perez, J. (2015). Biological treatments in atopic dermatitis. J. Clin. Med. 4, 593-613. doi: 10.3390/jcm4040593

Morar, N., Willis-Owen, S. A., Moffatt, M. F., and Cookson, W. O. (2006). The genetics of atopic dermatitis. J. Allergy Clin. Immunol. 118, 24-34. doi: 10.1016/j.jaci.2006.03.037 quiz 35-6.

Ohira, K., and Miyakawa, T. (2011). Chronic treatment with fluoxetine for more than 6 weeks decreases neurogenesis in the subventricular zone of adult mice. Mol. Brain 4:10. doi: 10.1186/1756-6606-4-10

Pellegrino, T. C., and Bayer, B. M. (2002). Role of central 5-HT(2) receptors in fluoxetine-induced decreases in T lymphocyte activity. Brain Behav. Immun. 16, 87-103. doi: 10.1006/brbi.2001.0625 
Piloto Valdes, L., Gomez Echevarria, A. H., Valdes Sanchez, A. F., Ochoa Ochoa, C., Chong Lopez, A., and Mier Naranjo, G. (1990). Atopic dermatitis. Findings of skin biopsies. Allergol. Immunopathol. (Madr) 18, 321-324.

Pinna, G., Costa, E., and Guidotti, A. (2009). SSRIs act as selective brain steroidogenic stimulants (SBSSs) at low doses that are inactive on 5-HT reuptake. Curr. Opin. Pharmacol. 9, 24-30. doi: 10.1016/j.coph.2008.12.006

Snapper, C. M., and Paul, W. E. (1987). Interferon-gamma and B cell stimulatory factor-1 reciprocally regulate Ig isotype production. Science 236, 944-947. doi: 10.1126/science.3107127

Stander, S., Bockenholt, B., Schurmeyer-Horst, F., Weishaupt, C., Heuft, G., Luger, T. A., et al. (2009). Treatment of chronic pruritus with the selective serotonin re-uptake inhibitors paroxetine and fluvoxamine: results of an openlabelled, two-arm proof-of-concept study. Acta Derm. Venereol. 89, 45-51. doi: 10.2340/00015555-0553

Wahlgren, C. F. (1992). Pathophysiology of itching in urticaria and atopic dermatitis. Allergy 47, 65-75. doi: 10.1111/j.1398-9995.1992.tb05091.x

Weidinger, S., and Novak, N. (2015). Atopic dermatitis. Lancet 387, 1109-1122. doi: 10.1016/S0140-6736(15)00149-X

Yoon, H. J., Jang, M. S., Kim, H. W., Song, D. U., Nam, K. I., Bae, C. S., et al. (2015). Protective effect of diet supplemented with rice prolamin extract against
DNCB-induced atopic dermatitis in BALB/c mice. BMC Complement. Altern. Med. 15:353. doi: 10.1186/s12906-015-0892-0

Zheng, J., Xu, D. F., Li, K., Wang, H. T., Shen, P. C., Lin, M., et al. (2011). Neonatal exposure to fluoxetine and fluvoxamine alteres spine density in mouse hippocampal CA1 pyramidal neurons. Int. J. Clin. Exp. Pathol. 4, 162-168.

Zylicz, Z., Krajnik, M., Sorge, A. A., and Costantini, M. (2003). Paroxetine in the treatment of severe non-dermatological pruritus: a randomized, controlled trial. J. Pain Symptom Manage. 26, 1105-1112. doi: 10.1016/j.jpainsymman.2003.05.004

Conflict of Interest Statement: The authors declare that the research was conducted in the absence of any commercial or financial relationships that could be construed as a potential conflict of interest.

Copyright (C) 2016 Li, Chen, Du, Huang, Han and Dong. This is an open-access article distributed under the terms of the Creative Commons Attribution License (CC BY). The use, distribution or reproduction in other forums is permitted, provided the original author(s) or licensor are credited and that the original publication in this journal is cited, in accordance with accepted academic practice. No use, distribution or reproduction is permitted which does not comply with these terms. 